\title{
Study of Short Column Behavior Originated from the Level Difference on Sloping Lots during Earthquake (Special Case: Reinforced Concrete Buildings)
}

\author{
Keyvan Ramin ${ }^{1 *}$, Foroud Mehrabpour ${ }^{2}$ \\ ${ }^{1}$ Department of Structural Engineering, Aisan Disman Consulting Engineers, Kermanshah, Iran \\ ${ }^{2}$ Department of Civil Engineering, Sciences \& Research Branch of Islamic Azad University, Kermanshah, Iran \\ Email: ${ }^{*}$ keyvan ramin@yahoo.com, ${ }^{*}$ aisandisman.co@gmail.com, foroodmehrabpour@yahoo.com
}

Received 19 October 2013; revised 19 November 2013; accepted 26 November 2013

Copyright (C) 2014 by authors and Scientific Research Publishing Inc.

This work is licensed under the Creative Commons Attribution International License (CC BY).

http://creativecommons.org/licenses/by/4.0/

(c) (i) Open Access

\section{Abstract}

The disorders originated from architectural design in buildings, show in different forms. One of them is the level difference originated from lot's slope which affects structures through short column phenomenon. The great stiffness of short columns enables them to absorb large amounts of structural energy. Inattention of some manuals and regulations such as Earthquake regulations to this phenomenon necessitates paying further attention to it. On this basis, the present study employed experimental modeling and numerical modeling for a four-story reinforced concrete building that involves the analysis of simple 2-D frames of varying floor heights and varying number of bays using a very popular software tool STAAD Pro on both a sloping and a flat lot. Also Sap2000 software had been used to show that the displacement of floors is greater for a flat lot building than a sloping lot building. However, the increase in shear was found to be quite greater in short columns compared to common ones and an enormous moment should be tolerated by sloping lot structures. The greater stiffness of the structure was also revealed by non-linear static (Push-Over) analysis. According to the results, short column are required to have more resistant sections and are suggested to be reinforced with more bars. In addition, more steel should be used as stirrups than as longitudinal bars. Also for existing structures, shear capacity of short columns should be retrofitted by FRP, Steel Jacket or other materials.

\section{Keywords}

Short Column; Reinforced Concrete; Level Difference; Slope; Earthquake

\footnotetext{
${ }^{*}$ Corresponding author.
}

How to cite this paper: Ramin, K. and Mehrabpour, F. (2014) Study of Short Column Behavior Originated from the Level Difference on Sloping Lots during Earthquake (Special Case: Reinforced Concrete Buildings). Open Journal of Civil Engineering, 4, 23-34. http://dx.doi.org/10.4236/ojce.2014.41003 


\section{Introduction}

The earthquake catastrophe is one of the major reasons for destruction of buildings, engineering infrastructures, and social systems [1]. Iran is located on the largest fold of earth surface which spreads throughout Saudi Arabia-Eurasia region with a surface area of 3,000,000 $\mathrm{km}^{2}$. Therefore, Locating on Alp-Himalaya chain, Iran is one of the most seismically-active regions for which a lot of destructive earthquakes have been recorded [2]. For example, a magnitude-6.6 earthquake hit southeast Iran on December 26, 2003 resulting in thousands of casualties and completes destruction of Bam city. The total number of killed people was estimated to be 80,000 . Such a disaster happened not only because of the large magnitude of earthquake but also as a result of non-standard structures and weak buildings. However, re-construction cost more than 10 billion dollars [3]. According to our experience from past earthquakes, disordered structures show higher potential for destruction in comparison with other ones. Structures suffer from such disorders mostly because of architectural considerations, beauty, or technical necessities [4]. Taking the general slope (north to south) of Tehran city into account, some of these considerations lead to the disorder in building height which appears as the destructive phenomenon of short column at the lowest floor. Figure 1 illustrates the short column phenomenon originated from construction of the building on a sloping lot. The majority of reinforced concrete columns are subjected to primary stresses caused by flexure, axial force, and shear. Secondary stresses associated with deformations are usually very small in most columns used in practice. These columns are referred to as "short columns". The capacity of a short column is the same as the capacity of its section under primary stresses, irrespective of its length.

The chief role of this column is to transfer the inertia force originated from earthquake to columns. The main part of these forces is exerted on the short column since the stiffness varies from column to column. Thus, the short column shows an enormous potential for serious damage by earthquake in the case of an inappropriate design. The column stiffness is reversely proportional to the third power of height. Therefore, the stiffness and energy absorption capacity of column gets 8 times greater as its length falls by half [5]. Figure 2 shows both a short and a long column.

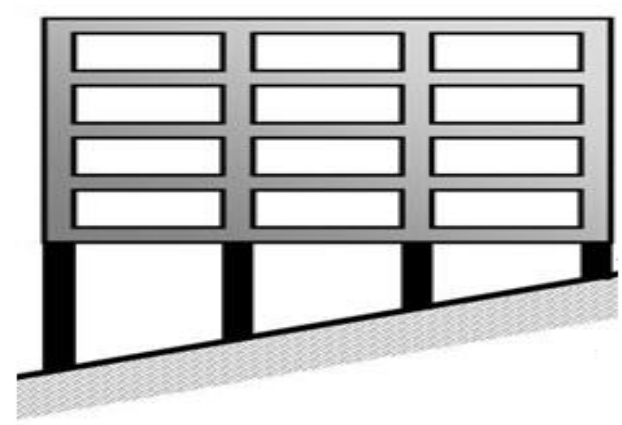

Figure 1. The position of columns on a sloping lot and generation of short column phenomenon [5].

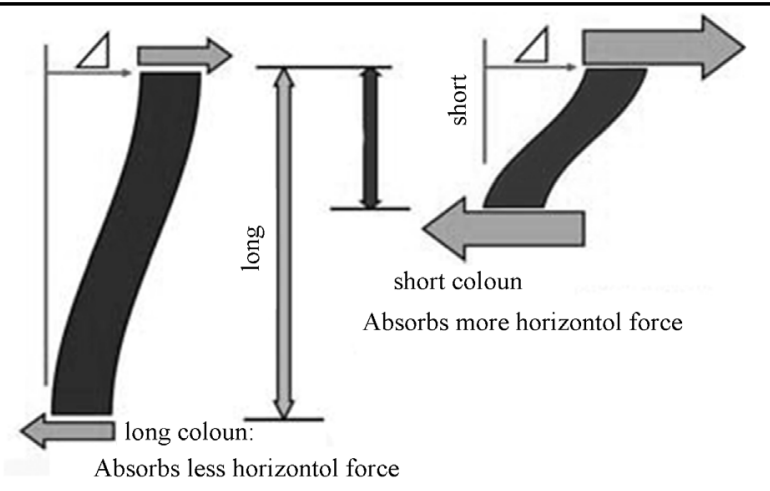

Figure 2. Comparison between a short column and a long column [5]. 
On the other hand, the common approach to structural design does not predict the strength or weakness of columns and beams. Hence it is expected such a structure will be destroyed. Considering the mentioned facts, it is necessary to carry out researches on this type of columns in order to suggest some special designs for construction on sloping lots. Plenty of related researches can be found in literature. For instance, Moretti and Tassios studied the seismic design with small shear ratio as well as the seismic behavior of 8 reinforced concrete short columns under constant axial load and static cyclic displacements by measuring the strains of concrete and steel. They suggested a new model of truss with the ability to distribute forces inside the columns in order to simulate the behavior of reinforced concrete short columns and thence, to better understand the mechanism of destruction [6] [7]. In 2008, Reference [8] found that FRP completely changes the rupture modulus in columns so that it changes from brittle to flexible in a completely reinforced column. When columns are reinforced with the bands placed at constant distances, rupture occurs at flexural-shear modulus. Liang and Fragomeni have suggested a general model for non-linear non-elastic analysis and design of the concrete-filled steel short columns under axial loads as well as an accurate structural model for the high-resistance and medium-resistance concrete enclosed inside cylindrical short columns. They have also employed numerical methods to model the non-linear behavior of cylindrical columns [9]. Finally, Zho and Lilu investigated the behavior of quadrilateral and cylindrical SRC short columns under cyclic and axial loadings and found that steel pipes prevent shear failure of concrete more efficiently in cylindrical columns than in quadrilateral ones [10]. Although in many of sloping grounds, often structures constructed on two or more levels of foundation. Schematic model of two levels of foundation is indicated in Figure 3.

\section{Modeling and Study Methodology}

The present study investigates and compares two four-story reinforced concrete moment resisting frame (MRF) buildings with medium deformability, one of which is located on a flat lot and the other one is on a lot sloped by 20 degrees (Figure 4). The plans of both buildings are completely symmetric and similar to each other. Both have joist and filling block ceilings, designed for residential use on a second type soil ground and located in a region with relatively high risk of earthquake [11]. Moreover, their loading condition [12] and material properties are the same. The modeling and linear static analysis and design were carried out using ETABS2000 software, while SAP2000 software was employed for non-linear static analysis of the structures. The joints used for beams and columns were M3 and PM2M3 joints, respectively [13]. Dimensions of the columns were $40 \times 40$ for first and second floors and $35 \times 35$ for third and fourth floors, while the dimensions of beams were $40 \times 35$ for first two floors and $35 \times 30$ for second two floors.

\section{Short Column Effect}

Short column effect arises when a column in a RC frame building is restricted from moving owing to any obstruction. The obstruction can be:

1) Presence of unreinforced masonry infills of partial height of adjoining RC column;

2) Conditions arising from sloping ground, when some basement columns are shorter than others;

3) Presence of a mezzanine slab (which meets the columns at an intermediate height between the usual beamslab system of the floors in RC buildings);

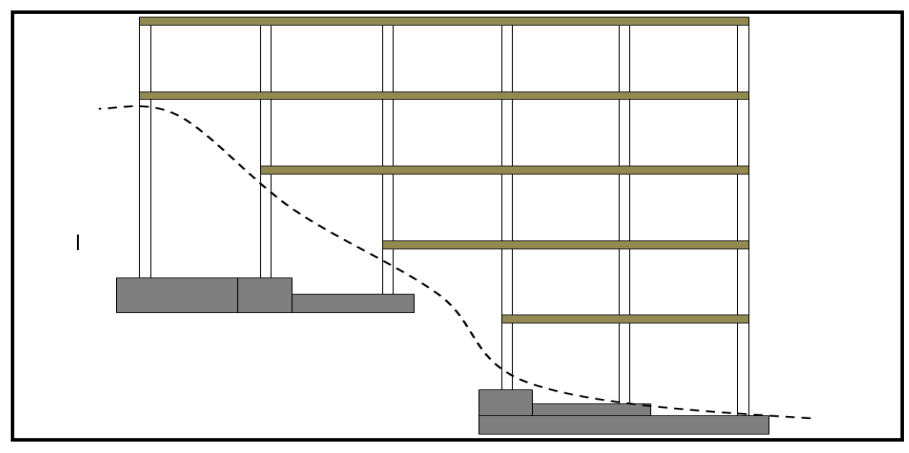

Figure 3. Schematic model of different level foundations. 


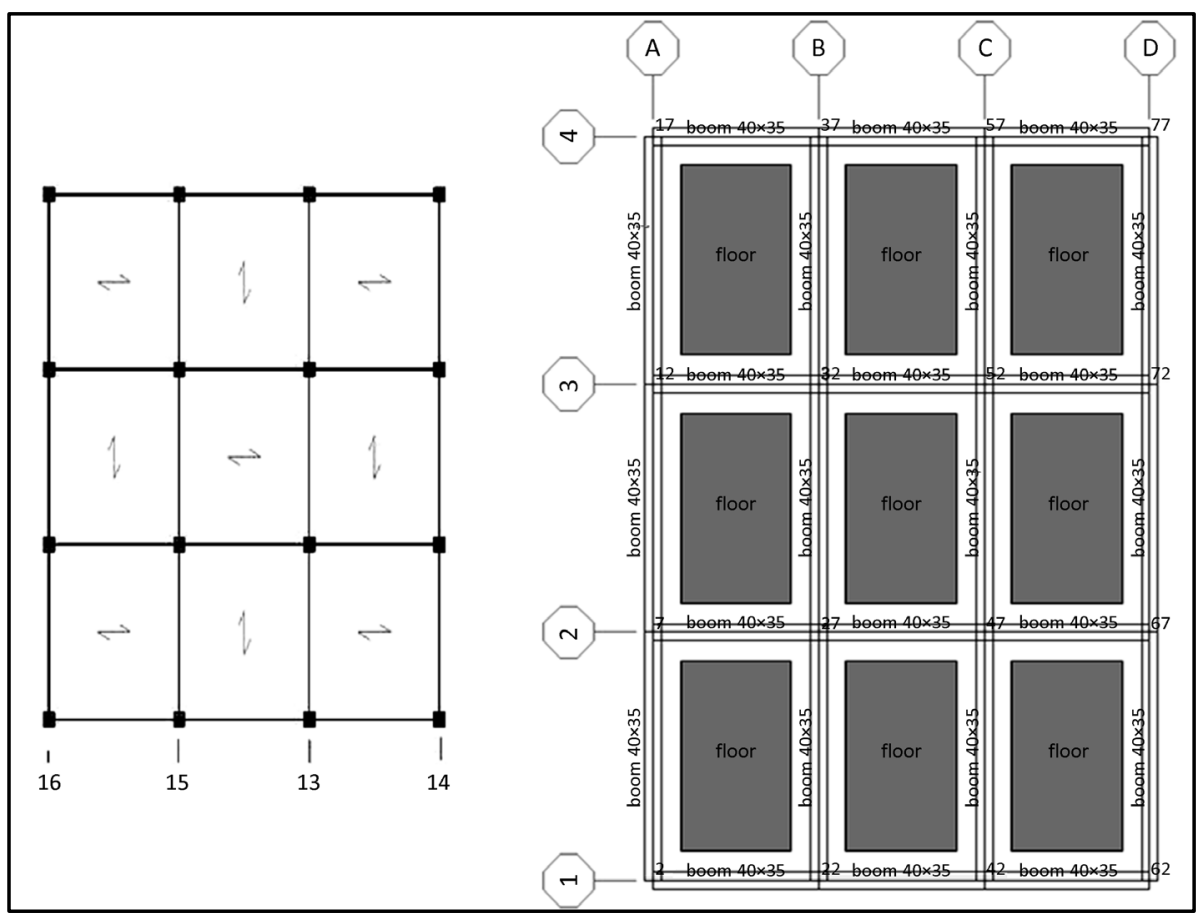

(a)

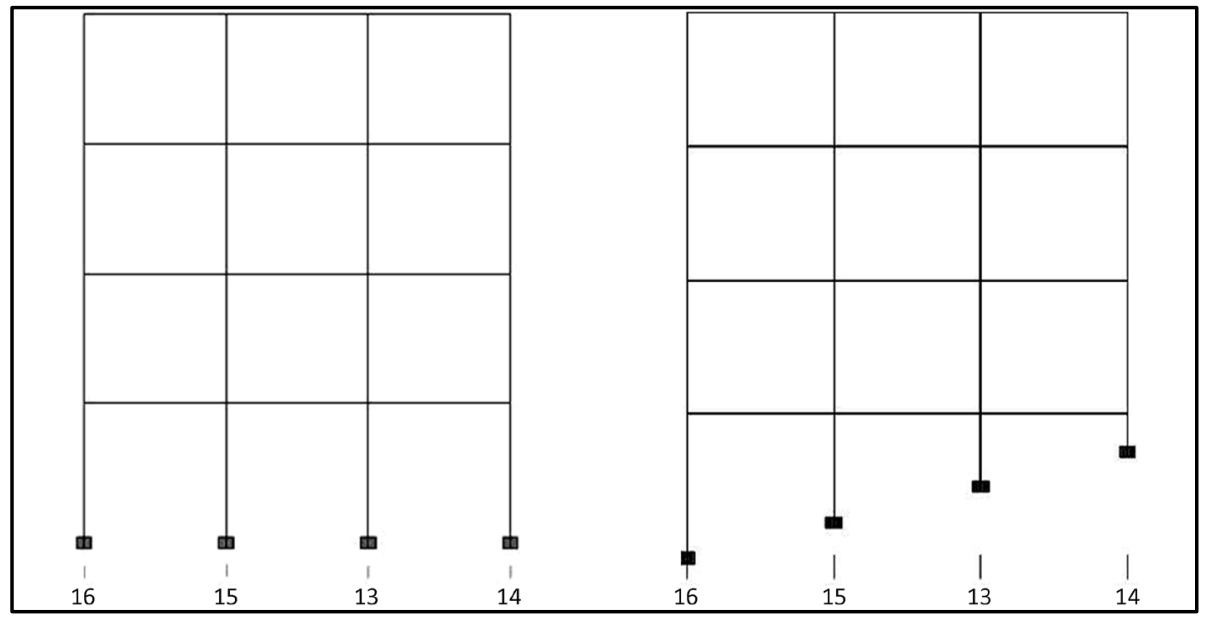

(b)

(c)

Figure 4. Plans and frames (along X-coordinate) of the studied structures. (a) The considered plan of both structures; (b) The flexural frame for the structure on flat lot and (c) The flexural frame for the structure on sloping lot.

4) Presence of a staircase beam/slab or K-braces on building columns (which meets the columns at an intermediate height between the usual beam-slab system of the floors in RC buildings) and;

5) Presence of a plinth beam making the height of the column below it to be shorter than that of the column above.

Effective height of column over which it can bend is restricted by adjoining items mentioned above.

Since lateral stiffness of columns is inversely proportional to the cube of its height, this short column effect is more severe when heights over which the columns are prevented from moving is large (or the unrestricted height of columns is small). However in present time we have new regulations in place for construction that greatly contribute to earthquake disaster mitigation and are being in applied in accordance with world practice [14].

In the regulations adopted for implementation in Iran the following factors have been found to be critically 
important in the design and construction of seismic resistant buildings.

\section{Modeling, Analysis and Design Assumptions}

\subsection{Loads}

Dead, Live, load and Earthquake Load by assumptions as below:

- Zone-III ( $\mathrm{Z}=0.16)$;

- Special revisiting moment frame $(\mathrm{RF}=5)$;

- Importance factor $=1$;

- Soil type medium;

- RC frame;

- Damping ratio $=5 \%$;

- Self weight of the structure.

- UBC 94 load in global x \& y directions

- Beams : $6 \mathrm{kN} / \mathrm{m}$ in global X \& Y downward for beams at perimeter.

\subsection{Analysis Types}

P-delta, modal, linear and non-linear static analyses are used in this research paper.

\subsubsection{Concrete Design}

- Consider all the load cases.

- Parameters: ultimate tensile strength of steel-415 N/sq· mm.

- Concrete strength: $30 \mathrm{~N} / \mathrm{sq} \cdot \mathrm{mm}$.

- Clear cover: $30 \mathrm{~mm}$.

- Centre to centre distance of each beam-4 m.

- Height of each storey.

1) First the structure is on level ground all the supporting columns being of $4 \mathrm{~m}$ height (3.2 $\mathrm{m}$ for other stories).

2) For the second case the related frame design for same loading combinations but on a sloping ground of 20 percent.

3) Each beams lengths are equal to $5 \mathrm{~m}$ for $\mathrm{Y}$ direction and $3.8 \mathrm{~m}$ for $\mathrm{X}$ direction.

Various models have been modeled in STAAD. Pro software. According to Figure 5, the two dimension structural frames with different base support conditions have been modeled for frames by existing short column. Design assumptions are applied in modeling process. After modeling samples, deformed shape frame in accordance to first mode shape was considered. From Figure 6 is clear that in irregular frames, short column's support conditions, is affected on whole frame's deformation vastly. Also in several initial story columns with hinge support of frame models, the axial force of column elements was increased. The measure of shear force in echelon frame system was investigated in other consideration and the increasing shear force in hinge base support in all stories observed. It could be deterioration for sloping ground structures. The significant bending moment is created in first and second stories of echelon frame in the form of hinge support, whereas this measure is created in upper stories of the same echelon frame by rigid base supports.

The short column effect also occurs in columns that support mezzanine floors or loft slabs that are added in between two regular floors.

There is another special situation in buildings when short-column effect occurs. Consider a wall (masonry or RC) of partial height built to fit a window over the remaining height [15]. The adjacent columns behave as short columns due to presence of these walls. In many cases, other columns in the same storey are of regular height, as there are no walls adjoining them. When the floor slab moves horizontally during an earthquake, the upper ends of these columns undergo the same displacement.

\subsubsection{The Results of Equivalent Static Analysis}

It is obvious from Figures 7 and 8 that the displacement of floors is greater for the common structure since the columns are longer for it. This difference in column height is bigger for first-floor columns so that the displace 


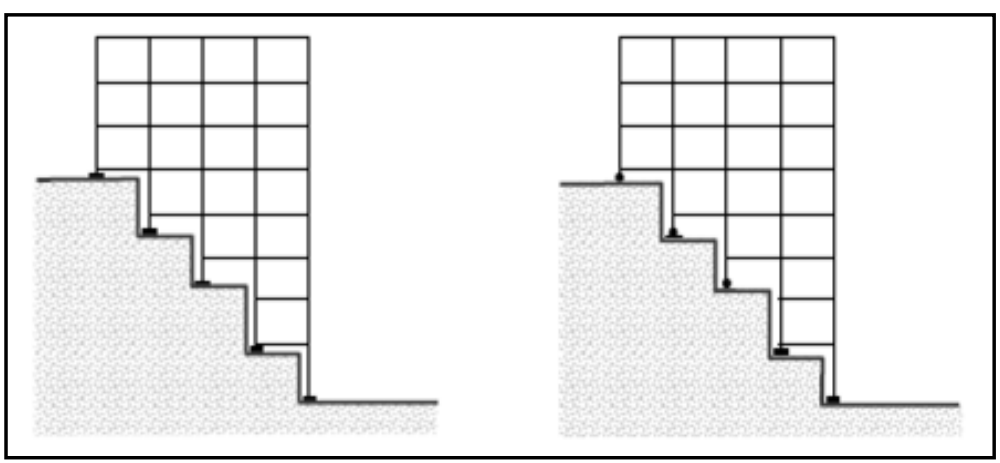

Figure 5. Buildings on slope: Stiffness irregularity in elevation due to unequal length of columns and degree of fixity at column base.

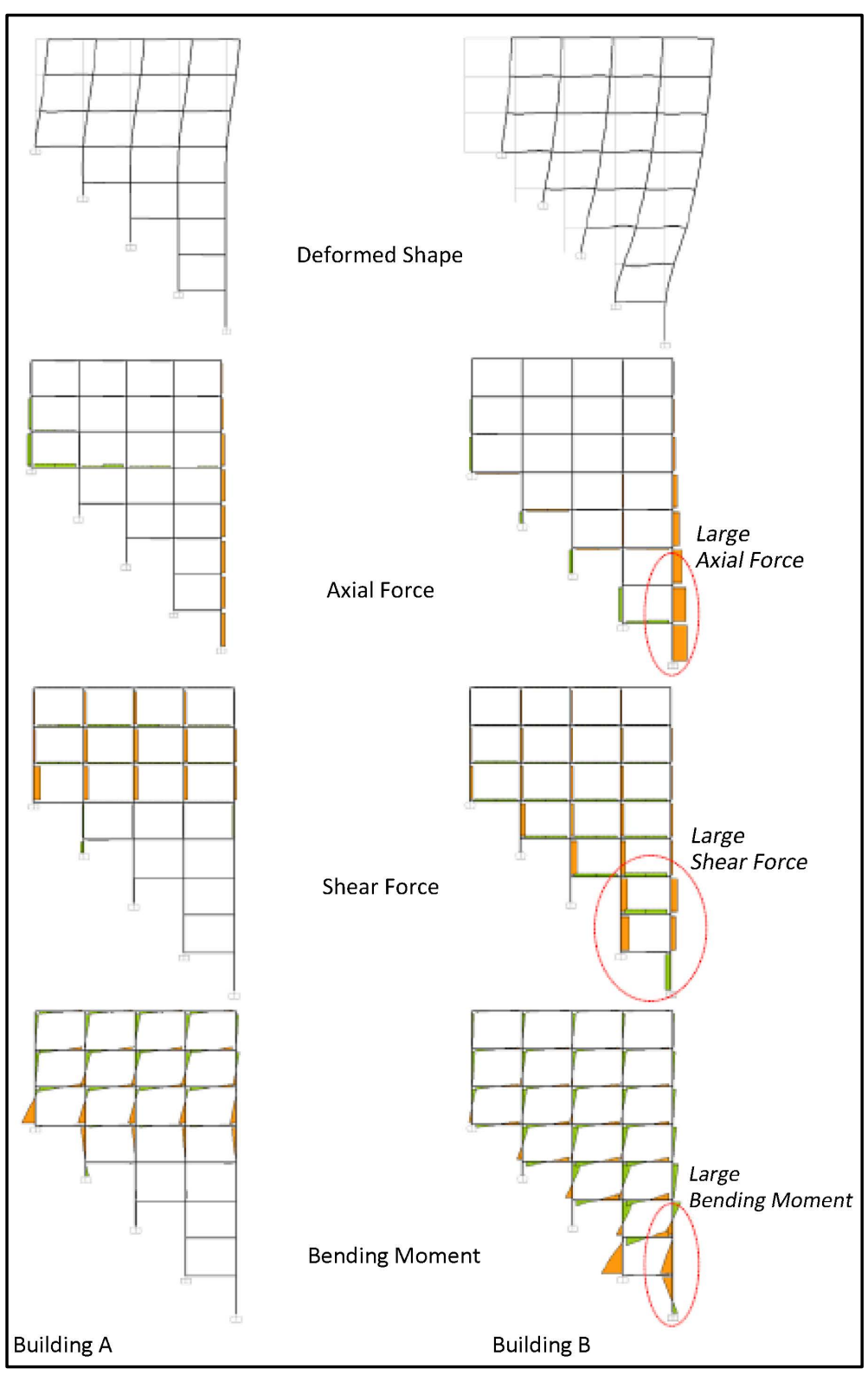

Figure 6. Buildings on slope: Deformation and force distribution. 


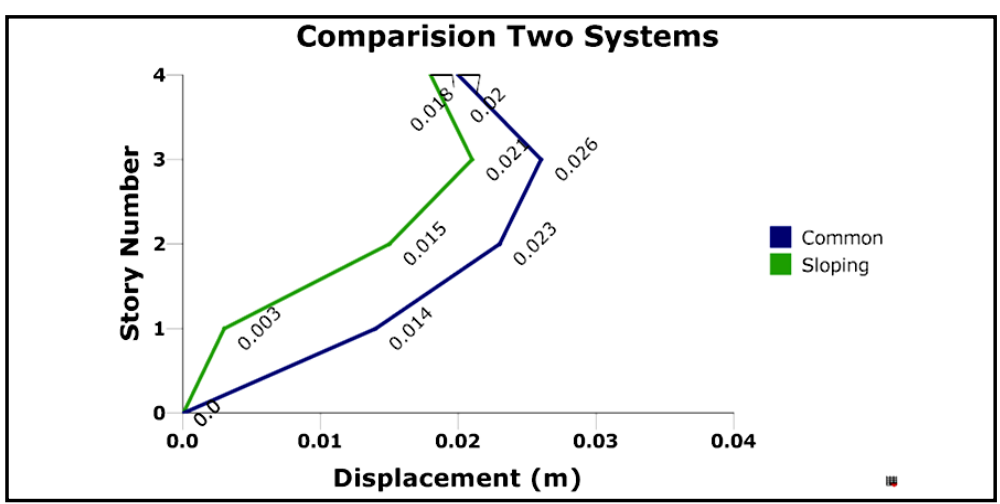

Figure 7. Displacement of floors in the direction of X.

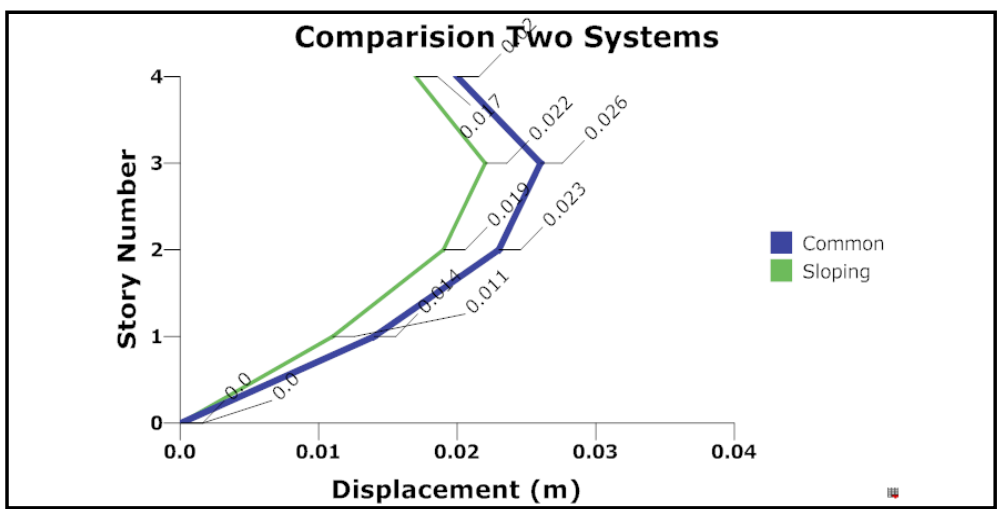

Figure 8. Displacement of floors in the direction of Y.

ment is six times greater for the common structure than for the structure on sloping lot. Therefore, the mean height of first floor columns is smaller in the latter structure. This turns the first floor to a floor of relatively-high rigidity and stiffness which, in turn, results in its smaller displacement in the case of an earthquake. According to the plots, this difference is minimized for upper floors where the amount of displacement is roughly the same (just 1.2 times greater for common structure than for the structure of sloping lot). However, the short column is stiffer as compared to the tall column, and it attracts larger earthquake force. Stiffness of a column means resistance to deformation - the larger is the stiffness, larger is the force required to deform it. If a short column is not adequately designed for such a large force, it can suffer significant damage during an earthquake.

Figures 9-12 show that the relative rotational stiffness of short column the locations of foundation and connection nodes with beams and upper floor columns is greater compared to that of the corresponding columns in common structures and hence, greater moment should be tolerated by short columns. This ratio is proportional to the column height, that is, as the column length increases; the moment adsorption is expected to rise. Since the effective height over which a short column can freely bend is small, it offers more resistance to horizontal motion and thereby attracts a larger force as compared to the regular column. As a result, short column sustains more damage. The contribution of short column to the adsorption of bending moment and the shear force originated from seismic loads is 9 times greater than that of other columns but in common structures, columns have an equal contribution to bending moment and base shear because of their equal stiffness.

The behaviour of sloping lots buildings differs significantly from the regular buildings on flat ground. The sloping lots buildings are subjected to significant torsional effects under cross-slope excitation. Under alongslope excitation, the varying heights of columns cause stiffness irregularity, and the short columns resist almost all of the storey shear. The linear and non-linear analysis shows that the storey at specific level, in case of sloping lots buildings, is most susceptible to damage.

Torsion may damage columns and cause their shear failure to occur before bending failure of beams resulting in the destruction of whole structure. In Figure 13, the torsional moment of columns in both structures are compared to each other. 


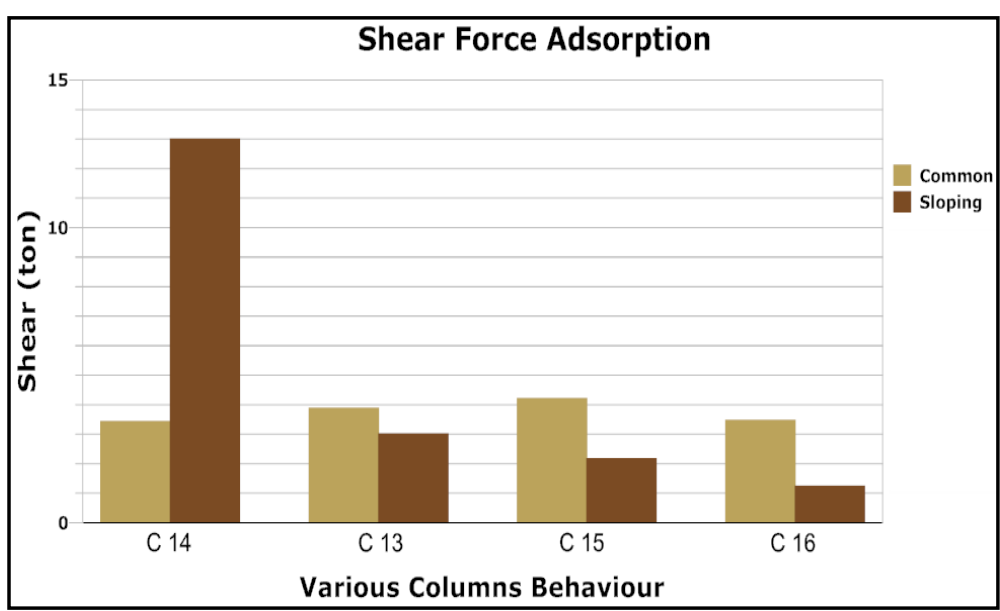

Figure 9. Plot of first floor columns' shear in the direction of X.

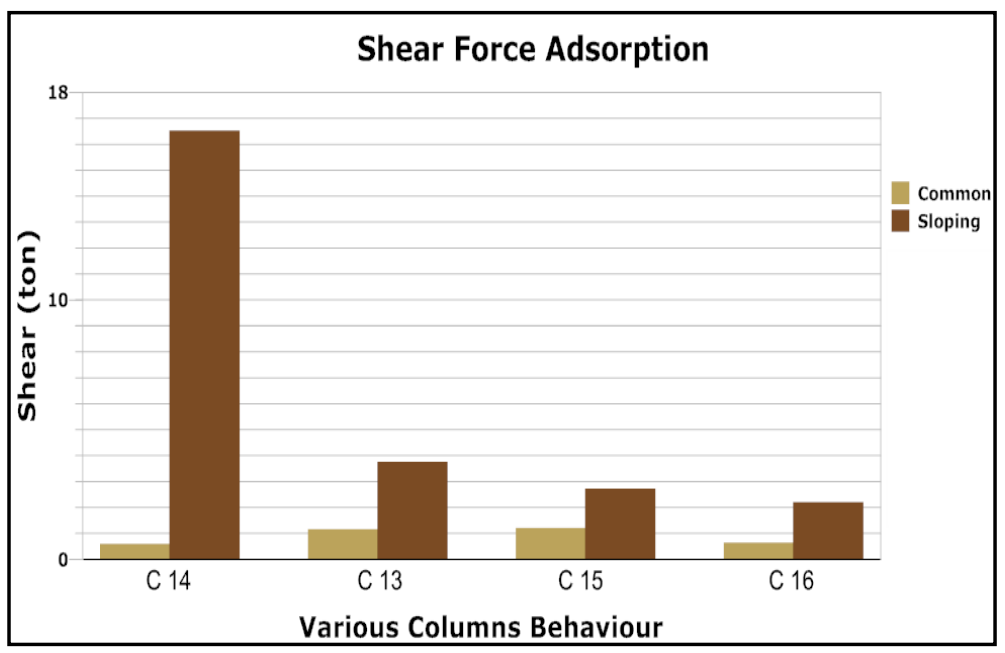

Figure 10. Plot of first floor columns' shear in the direction of Y.

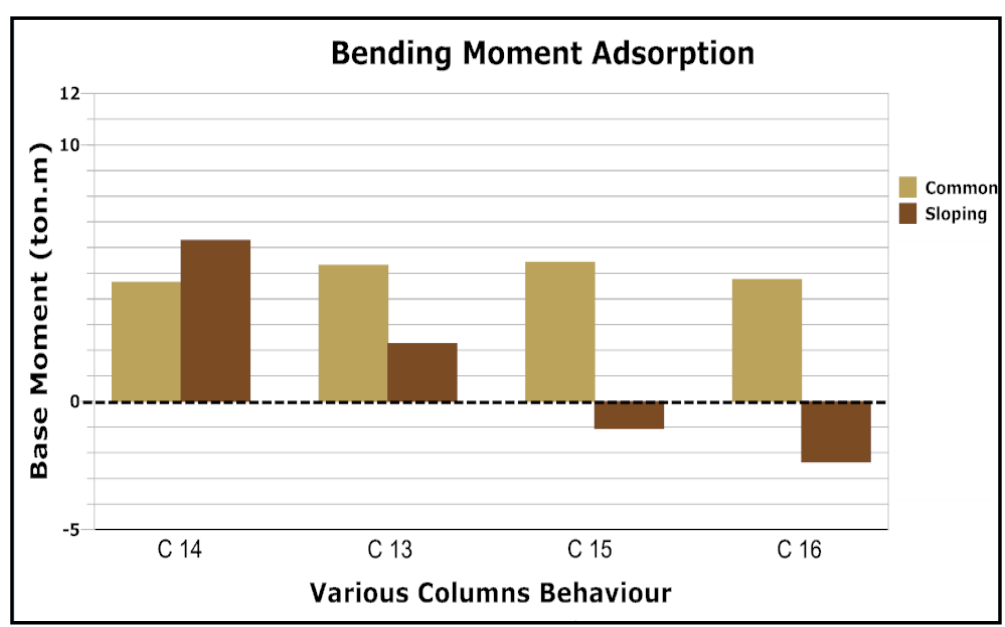

Figure 11. Plot of first floor columns' base moment in the direction of X.

Torsion takes place just on the sloping lot structure because of the inequality in the height of different columns which leads to the different amounts of columns' displacement and hence, the considerable torsion of 


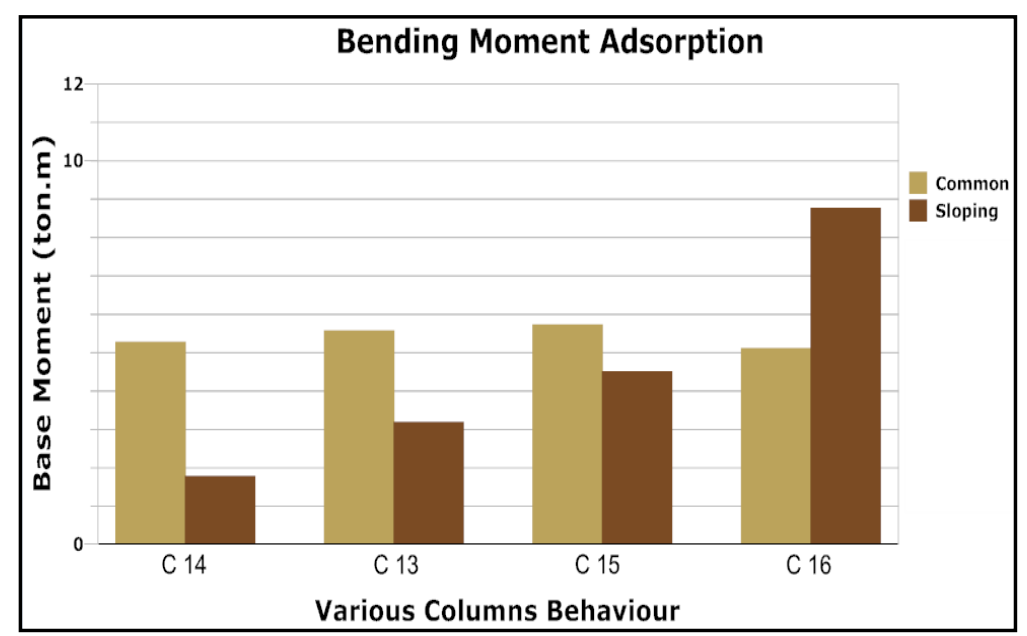

Figure 12. Plot of first floor columns' base moment in the direction of Y.

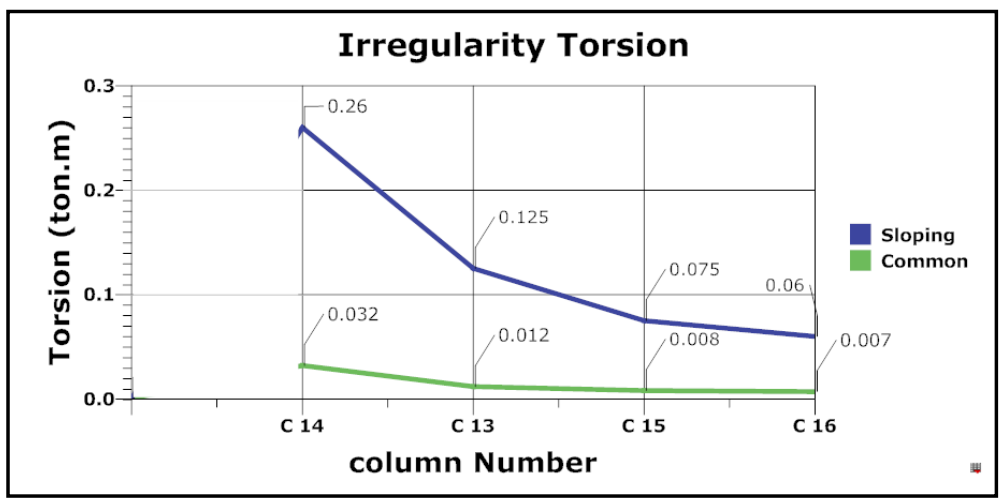

Figure 13. Plot of first floor columns’ torsional moment.

columns, first floor, and finally entire structure. It is worth mentioning that no torsion was observed for common structure.

Figure 14 compares the values of common and sloping lot structures' period on first 12 modes. As a result of the increase in stiffness of the sloping lot structure, its natural frequency rises and hence, because of stiffness accession, It's period decreases so that it is smaller than the period of common structure for first three modes but the difference is not so clear after fourth mode.

In summary, natural periods of buildings depend on the distribution of mass and stiffness along the building (in all directions).

\subsubsection{The Results of Non-Linear Static Analysis}

According to Figure 15, the short columns in sloping lot structures have a section of higher steel content and more compact stirrups since the percentage of earthquake force absorption rises for this structure. Therefore, the resistance of sloping lot structure to lateral load is 12 percent greater than that of the common structure because of the increase in strain hardening. These results indicate more ductility of common structure and although more initial stiffness of sloping lot structure. The curvature area, which is a measure of structure's energy waste amount, is also greater for sloping lot structure as a result of its stronger design. The elastic behavior of two structures is also different so that the stiffness of sloping lot structure is larger because of its short columns.

After execution of non-linear static analysis of three dimensional samples, maximum amount of axial force, shear force, bending moment, tension and compression forces results concern about 10 beams in first floor from $\mathrm{X}$ and $\mathrm{Y}$ directions were considered randomly. In according to Table 1, axial force amount of selective beams in flat ground structure are more than sloping ground structure. It was happened because of further resultant amount of bending moment and shear force of column in flat ground. Maximum shear force and bending mo- 


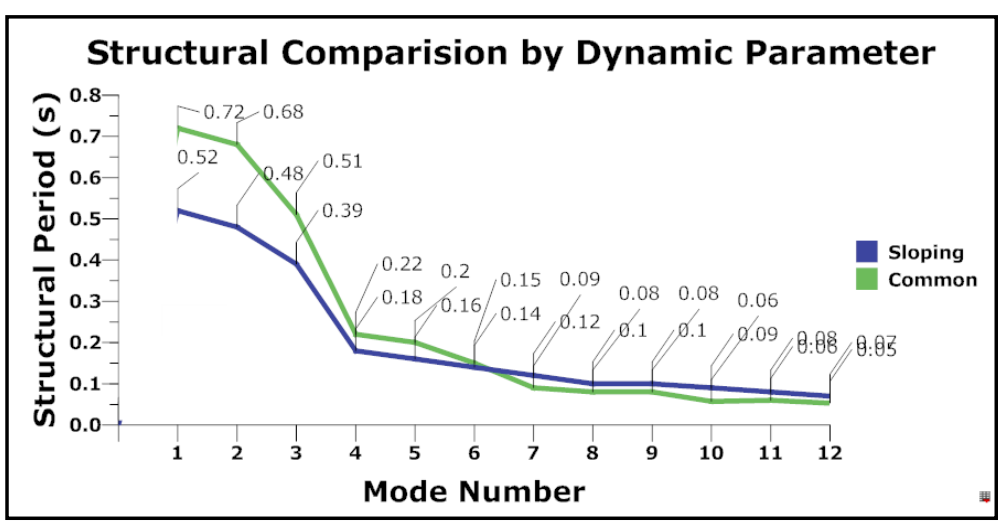

Figure 14. Plot of period for first 12 modes.

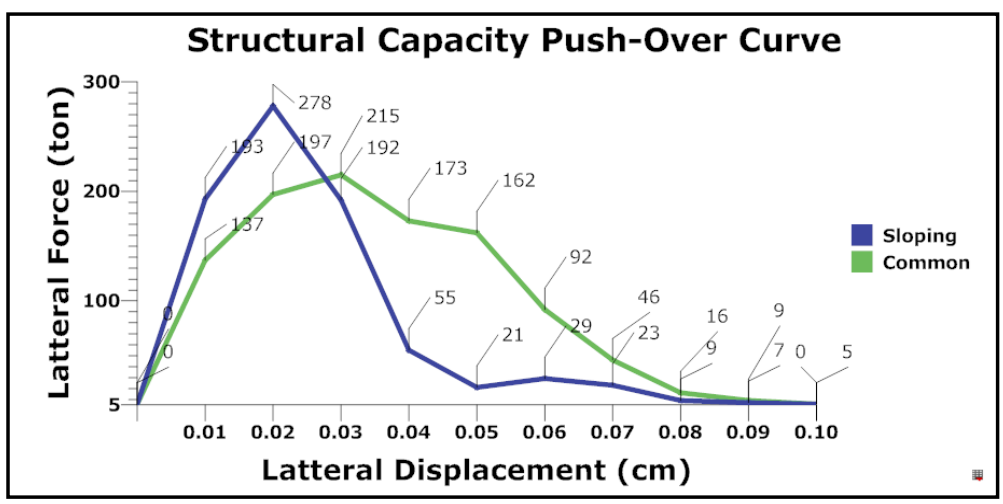

Figure 15. Plot of base shear-ceiling displacement (structure capacity spectrum).

ment of selective beams in flat ground structure were also greater than their measures in sloping ground structure. Other maximum forces were achieved for selective beams. Tension and compression force of flat ground structure are more than the sloping.

As for obtained results, because of short column effects and partial usage of column's section from its flexural capacity in sloping ground structure, their beams could not apply whole structural capacity. The beam capacity used in sloping ground structure was smaller than whole beam's capacity and hence, this could be an uneconomical design method.

As shown in Figure 16, for existing irregularity investigation of sloping ground structures, samples are modeled in finite element analysis software and the diaphragm's in-plane stresses are assessed for first floor's slab. Because of torsion in plan of sloping ground model, the effect of stiffness irregularity and the distance between mass center and stiffness center (eccentricity), the high levels of in-plane stresses were caused in the form of out-of-plane forces and torsion of plan. That it could be a significant deterioration for the sloping ground structure.

\section{Conclusions}

Comparing the results obtained from shear, bending and torsional moment, period, and displacements plots of two four-story reinforced concrete structures built on a flat lot and a sloping lot under the similar conditions, it is concluded that:

In short columns, because of their shorter height, a considerable increase in stiffness of their section is observed while the percentage of shear force absorption and bending moment rises. Thus, the section of these columns is required to contain more steel to provide a greater resistance. This ratio will not be equal and the amount of shear will extensively increase as the height decreases resulting in the higher steel content of stirrups compared to longitudinal bars. 
Table 1. Analysis results for 3 bay systems on plane and on a sloping ground for four story frame.

\begin{tabular}{|c|c|c|c|c|c|c|c|c|c|c|}
\hline \multirow{3}{*}{$\begin{array}{c}\begin{array}{c}\text { Beam } \\
\text { model no. }\end{array} \\
\text { kN }\end{array}$} & \multicolumn{2}{|c|}{ Maximum axial force } & \multicolumn{2}{|c|}{ Maximum shear force } & \multicolumn{2}{|c|}{$\begin{array}{c}\text { Maximum bending } \\
\text { moment }\end{array}$} & \multicolumn{2}{|c|}{$\begin{array}{l}\text { Maximum } \\
\text { tensile force }\end{array}$} & \multicolumn{2}{|c|}{$\begin{array}{c}\text { Maximum } \\
\text { compresssive force }\end{array}$} \\
\hline & \multicolumn{2}{|c|}{$\mathrm{kN}$} & \multicolumn{2}{|c|}{$\mathrm{kN}-\mathrm{m}$} & \multicolumn{2}{|c|}{$\mathrm{N} / \mathrm{mm}^{2}$} & \multicolumn{2}{|c|}{$\mathrm{N} / \mathrm{mm}^{2}$} & \multicolumn{2}{|c|}{$\mathrm{kN}$} \\
\hline & $\mathrm{P}^{*}$ & $\mathrm{~S}^{*}$ & $\mathrm{P}$ & S & $P$ & S & $\mathrm{P}$ & $\mathrm{S}$ & $\mathrm{P}$ & $\mathrm{S}$ \\
\hline 1 & 372 & 283 & -26 & -18 & -51 & -45 & -2 & -2 & 5 & 4 \\
\hline 2 & 183 & 139 & -41 & -38 & 93 & -84 & -5 & -5 & 6 & 6 \\
\hline 3 & 767 & 635 & -18 & -18 & -41 & -46 & -1 & -3 & 5 & 5 \\
\hline 4 & 390 & 323 & -17 & -17 & -36 & -36 & -1 & -2 & 4 & 3 \\
\hline 5 & 767 & 635 & 26 & -28 & 51 & 59 & -2 & -3 & 5 & 4 \\
\hline 6 & 182 & 138 & 42 & 38 & -93 & -83 & -5 & -4 & 6 & 6 \\
\hline 7 & -26 & -27 & -174 & -156 & 147 & 131 & -9 & -8 & 9 & 8 \\
\hline 8 & 41 & 38 & -180 & -161 & 157 & 140 & -9 & -8 & 10 & 9 \\
\hline 9 & -26 & -27 & 174 & 156 & 148 & 133 & -9 & -8 & 9 & 8 \\
\hline 10 & 41 & 38 & 180 & 161 & 157 & 140 & -9 & -8 & 10 & 9 \\
\hline Max & 767 & 635 & 180 & 161 & 157 & 140 & -1 & -2 & 10 & 9 \\
\hline
\end{tabular}

$[\mathrm{P}=\text { Plane ground, } \mathrm{S}=\text { Sloping Ground }]^{*}$, Beams are selected from first story (1 to 5 from $\mathrm{X}$ direction and 6 to 10 from $\mathrm{Y}$ direction).

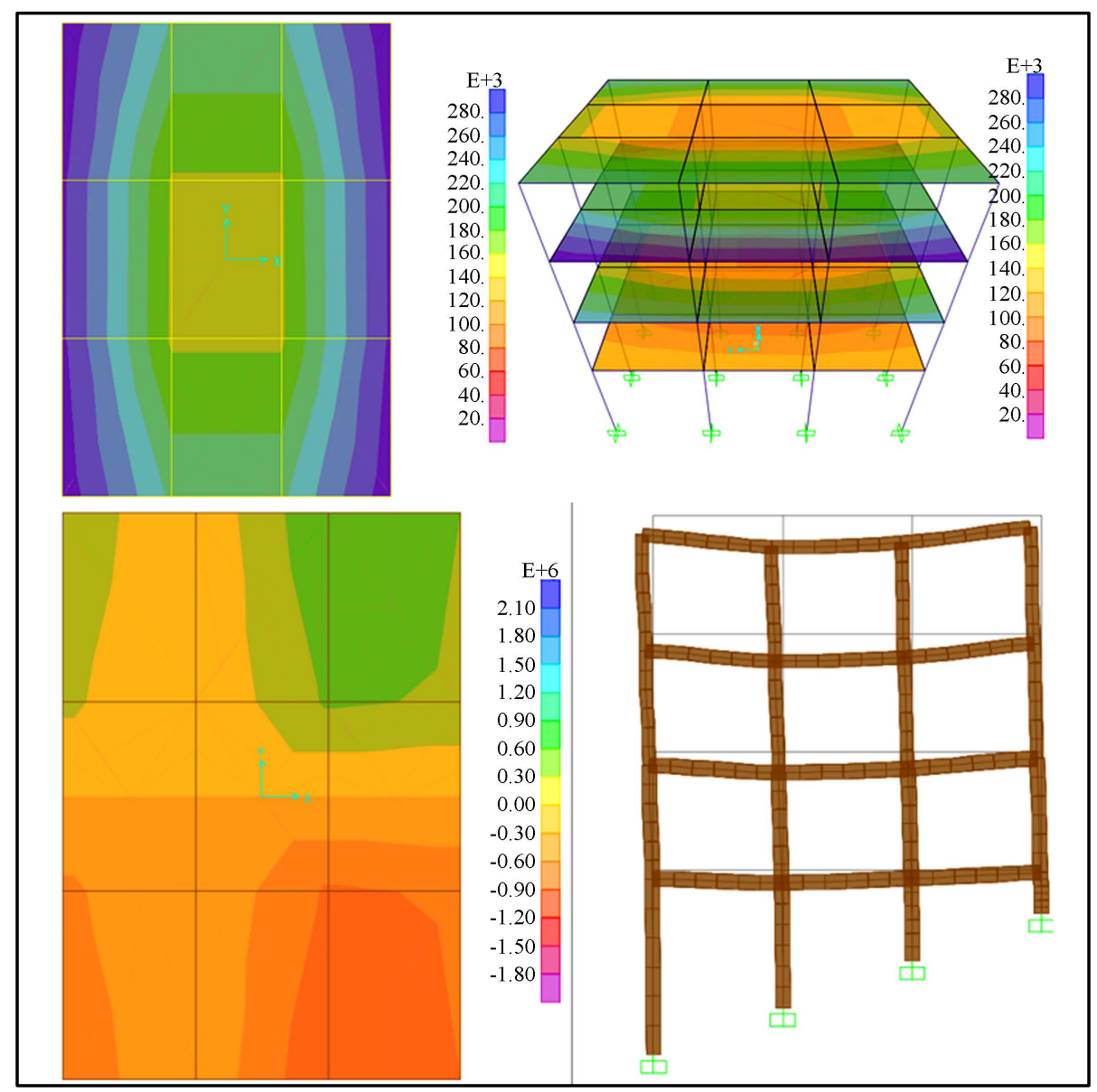

Figure 16. The maximum in-plane slab stresses contour in the structure on flat lot (top) and the maximum in-plane slab stresses contour in the structure on sloping lot (bottom). 
The existence of short columns in a floor raises its stiffness resulting in a reduction of relative displacement of the floor in some nodes (diaphragm to short column connections) and subsequently, the entire structure.

1) In the case of a difference in a floor's columns height, torsion will be expected to appear and is required to foreseen when designing the structure.

2) Results indicate more ductility of common structure and although more initial stiffness of sloping lot structure. The curvature area, which is a measure of structure's energy waste amount (energy dissipated), is also greater for sloping lot structure as a result of its stronger design.

As a result of the increase in stiffness of the sloping lot structure, its natural frequency rises and hence, because of stiffness accession, it's period decreases so that it is smaller than the period of common structure for first three modes but the difference is not so clear after fourth mode.

\section{References}

[1] Guan, Y.H., et al. (2011) Study on the Earthquake Disaster Reduction Information Management System and Its Application. International Journal of Intelligent Systems and Applications, 1, 51-57. http://dx.doi.org/10.5815/ijisa.2011.01.07

[2] Gourabi, A. and Yamani, M. (2011) Active Faulting and Quaternary Landforms Deformation Related to the Nain Fault. American Journal of Environmental Sciences, 7, 441-447. http://dx.doi.org/10.3844/ajessp.2011.441.447

[3] Amiri, A. and Tabatabaei, R. (2008) Earthquake Risk Management Strategy Plan Using Nonparametric Estimation of Hazard Rate. American Journal of Applied Sciences, 5, 581-585. http://dx.doi.org/10.3844/ajassp.2008.581.585

[4] Kheyroddin, A. and Amiri, A. (2009) Study of the Effect of Braced Frames Position on Behavior of Duplex Structures with Different Floor Levels Considering the Short Column Phenomenon. Research Bulletin of Seismology and Earthquake, 3, 26-36.

[5] Murty, C.V.R. (2004) Why Are Short Columns More Damaged during Earthquakes? Indian Institute of Technology Kanpur.

[6] Moretti, M. and Tassios, T.P. (2007) Behaviour of Short Columns Subjected to Cyclic Shear Displacements: Experimental Results. Engineering Structures, 2, 2018-2029. http://dx.doi.org/10.1016/j.engstruct.2006.11.001

[7] Moretti, M. and Tassios, T.P. (2006) Behaviour and Ductility of Reinforced Concrete Short Columns Using Global Truss Model. ACI Structural Journal, 103, 319-327.

[8] Colomb, F., Tobbi, H., Ferrier, E. and Hamelin, P. (2008) Seismic Retrofit of Reinforced Concrete Short Columns by CFRP Materials. Composite Structures, 82, 475-487. http://dx.doi.org/10.1016/j.compstruct.2007.01.028

[9] Liang, Q.Q. and Fragomeni, S. (2009) Nonlinear Analysis of Circular Concrete-Filled Steel Tubular Short Columns under Axial Loading. Journal of Constructional Steel Research, 65, 2186-2196. http://dx.doi.org/10.1016/j.jcsr.2009.06.015

[10] Zhou, X. and Liu, J. (2010) Seismic Behavior and Strength of Tubed Steel Reinforced Concrete (SRC) Short Columns. Journal of Constructional Steel Research, 66, 885-896. http://dx.doi.org/10.1016/j.jcsr.2010.01.020

[11] The Regulation for Buildings Design against Earthquake (2006) Iranian Standard No.2800. The Iranian Center for Researches on Building and House, 3rd Edition.

[12] National Building Regulation, Sixth Topic (2007) Loads on Building. Ministry of Roads and Urban Development, Department of National Building Regulations Affairs.

[13] Publication 120, Department of Technical Affairs and Criteria Establishment (2002) Iranian Concrete Regulation (ICR). First Revision, The National Organization of Management and Programming.

[14] Ashimbayev, M.U., Itskov, I.E. and Lobodryga, T.D., (2004) Living with Natural and Technological Hazards, Topic a.2: Reducing Vulnerabilities in Existing Building and Lifelines. Seismic Hazard and Earthquake Engineering, 35, 43-46.

[15] Paul, D.K. and Kumar, S. (1997) Stability Analysis of Slope with Building Loads. Soil Dynamics and Earthquake Engineering, 16, 395-405. http://dx.doi.org/10.1016/S0267-7261(97)00008-0 